\title{
ARTE E ALTERIDADE: DIALOGANDO COM A ESCUTA DAS IDENTIDADES NO PRIMEIRO CICLO DO ENSINO FUNDAMENTAL
}

Johnny chaves de Oliveira ${ }^{\mathrm{i}}$

\section{Introdução}

O objetivo deste trabalho é problematizar as relações entre adultos e crianças na escola, examinando-as a luz do poder e da (in)disciplina. Como método de trabalho serão apresentadas as experiências do cotidiano escolar e as vivenciadas nos encontros com as crianças realizados semanalmente, com duração aproximada de 1(uma) hora, ao longo de um trimestre de pesquisa e observações. Os encontros foram resultados de uma demanda da escola e da coordenação do PIBID (Programa Institucional de Bolsas de Iniciação à Docência) que devido ao relato de comportamentos inadequados dos estudantes que eram considerados indisciplinados, uma vez que tais comportamentos prejudicavam o andamento das atividades.

Os sete "bagunceiros" selecionados para as reuniões foram, segundo a coordenação da escola, representativos do alto grau de desmotivação e expressavam sua necessidade de atenção através da desobediência, passividade e resignação nos encontros realizados, além da dificuldade de respeitar os colegas e no enfrentamento constante com a professora regente da turma. Em função desse quadro formulamos as seguintes questões: O que leva os jovens a serem indisciplinados na escola? Como a escola lida com a indisciplina no seu cotidiano? Essas são as questões principais que engendraram esse trabalho.

No discurso escolar, a indisciplina é em grande parte atribuída às influências familiares e/ou do meio onde indivíduo vive. Como resultado há uma relação de causa/consequência no sofrimento passivo da escola diante dos estudantes considerados bagunceiros que podem levar a queda de rendimento da turma. A escola cumpre com seu papel de transmissão de conhecimentos, principalmente, com os estudantes indisciplinados? Esse seria o mais importante e o único papel a ser atribuído à escola contemporânea diante dessas emergências educacionais?

Muitas indagações nortearam esse trabalho que foi ganhando consistência a partir das narrativas da "turminha do barulho" e das pistas presentes nas produções artísticas retratadas em cada encontro. A metodologia foi centrada na prática da roda de conversas e no 
uso da ferramenta artística para que eles expressassem as demandas desse grupo. A hipótese é que esses sete "artistas" no aparente ato inconsequente de "pintar o sete" (em referência à expressão que na linguagem popular significa fazer bagunça) poderiam reverberar uma desordem que tem muito a dizer sobre um cenário educacional instável, anacrônico e silenciador de uma "educação bancária", segundo as concepções de Paulo Freire, que independeria das pessoas envolvidas no processo por agir de fora para dentro.

O comprometimento do papel escolar como transmissor de conhecimentos interfere no êxito de uma educação crítica, reflexiva e transformadora desses indivíduos estigmatizados? Como opera esse silenciamento escolar diante do tratamento das chamadas "microviolências" ou "incivilidades cotidianas" apontadas segundo Bernard Charlot (2002)? Por que, então, essa problemática é invisibilizada nos discursos cotidianos da escola? As aulas tradicionais incoerentes com uma abordagem efetiva sobre a indisciplina podem se transformar, a partir das táticas utilizadoras de Certeau (1990), em "estratégias" diante das "táticas" das curiosidades sexuais nesse dilema pedagógico constantemente repressor?

A legislação define a temática da sexualidade como tema transversal e a formação dos professores não dá conta das inúmeras complexidades educacionais, além da dificuldade de se desprender de valores morais e de lidar conflituosamente com princípios religiosos durante o exercício da profissão. Constata-se uma ineficiente formação para uma abordagem consistente e pluralista acerca da sexualidade e até da indisciplina, corroborando com a dissonância efetiva entre o currículo oficial e o instituído na prática.

Partindo das situações vivenciadas nos encontros com os estudantes alguns dilemas foram enunciados, perguntas foram respondidas e outras indagações ganharam mais força ao longo nesse trabalho. Secundariamente, mas não menos importante cabe refletir sobre a relação entre os tons da indisciplina e as variadas cores das sexualidades. Por que se manifestam gestos da própria erotização nas salas? É simplesmente um mecanismo de escape, um "grito" frente à inadequação das aulas pouco atrativas a demanda deles? Seria mais uma estratégia resiliente diante das privações e limites impostos de forma assimétrica pelos adultos ou a indisciplina não apresenta nenhuma relação com a curiosidade sexual ou erotização nos espaços escolares?

\section{Desenvolvimento}


Inicialmente, foi levantado o perfil estatístico dos participantes e poderíamos caracterizá-los por serem estudantes moradores do entorno da unidade escolar, satisfeitos com a escola, que possuem pelo menos uma televisão e um computador em casa e que acessam a internet, as redes sociais somente com fins de diversão. Já foram reprovados pelo menos uma vez e/ou apresentam idade superior a correspondente do referido ano escolar ( $4^{\circ}$ ano). Os nomes utilizados serão fictícios e nas fotografias foram preservadas a identificação dos participantes com o intuito apenas de aprofundar e documentar as atividades realizadas para uma apreciação posterior, assim como as anotações nos dias de observação.

O trecho retirado do diário de campo intitulado como "O estranhamento" retrata os sentimentos e experiências iniciais de um pesquisador, cheio de anseios transformadores, que ao se deparar com a fala do estudante, viu no pessimismo e desmotivação do grupo a possibilidade de maiores investigações que pudessem desvelar as causas das atitudes consideradas indisciplinadas que comprometiam o andamento das aulas. As expectativas e as frustrações de ambos os lados, dos educandos e dos educadores fazem parte do processo educacional e são combustíveis para o re-fazer pedagógico contínuo. Implicitamente, houve a necessidade de uma postura doutrinadora requerida nas conversas informais com a equipe pedagógica que atribuía à figura masculina do oficineiro uma possível mudança no comportamento da "turminha da bagunça"- como alguns a chamavam.

\footnotetext{
"Arrumei a sala, sem tantos obstáculos, nada que pudesse me atrapalhar na primeira oficina. Assim, poderia olhar para os sete ao mesmo tempo, afinal, só eram poucos bagunceiros não seria tão difícil assim. Avisaram-me que os buscariam e aquele friozinho na barriga me tomou. Eles me aceitariam ou me devorariam vivo... Em seguida, quis saber do relutante estudante por que eles estariam naquela oficina? Respondeu como se fosse óbvio: "Até parece que não sabe? A gente tá aqui porque fala palavrões, de sexo e brigamos na sala, por isso que mandaram a gente pra cá como castigo!".
}

As instituições escolares, assim como a família, caso se eximam da responsabilidade de orientar as crianças e/ou adolescentes contribuem equivocadamente com a cristalização das dúvidas, fantasias e curiosidades. Essa tarefa é suprida por terceiros, tornando anseios, medos e idéias precipitadas em tabus invioláveis. O ideal é que essa tarefa seja feita com cautela, tato e por pessoas com conhecimento especializado sobre os temas que pairam nas cabeças destes pulsantes seres que almejam respostas diante do silêncio social ou explicações meramente biológicas presentes nos livros. 
Desde 1996 que o Ministério de Educação (MEC) incluiu a sexualidade nos Parâmetros Curriculares Nacionais do Ensino Fundamental (PCNs), mas sua implementação prática nas escolas não engloba todos os três eixos básicos previstos: o corpo em sua dimensão erótica e reprodutiva como fonte e matriz da sexualidade; as relações de gênero, que são o conjunto de representações diferentes do sexo biológico; e a prevenção das DSTs/AIDS abordada sob a ótica das vulnerabilidades.

Entretanto, este último tem recebido maior atenção devido ao enfoque médico nos programas de saúde em detrimento do avanço esperado dos outros dois eixos para a vida das pessoas, tendo em vista que "as condições que possibilitaram a ampliação da discussão sobre a sexualidade também tiveram o efeito de aproximá-la das ideias de risco e ameaça, colocando em segundo plano sua associação ao prazer e à vida" (LOURO, 2004b: 36).

Podemos compreender que "as incivilidades se referem a condutas que se contrapõem às regras da boa convivência" (CHARLOT, 2002, p. 437). Entretanto, o estudo desse autor vem ao encontro de nossos anseios quando das ações ditas indisciplinadas surgem comportamentos desafiantes no âmbito pedagógico que rompem regras, esquemas da vida em sociedade e lançam prospectivas que podem extrapolar os contratos sociais escolares. Portanto, houve uma notória desconstrução dos preconceitos quanto aos termos empregados envolvendo a sexualidade, que reproduziam de maneira estereotipada até por desconhecimento ou ausência de elucidações por parte dos professores.

Segundo HECKERT (2004), o conceito de narrativa não se resume a um simples relato de acontecimentos, mas ao próprio acontecer. Sendo assim, os temas abordados nos encontros com as crianças foram se consolidando de acordo com a demanda narrada e suas relações com cada assunto. Almejou-se entender melhor e reinventar a maneira deles lidarem com a escola e com os estudos, proporcionando materiais diferenciados que pudessem fazêlos pensar através de uma lógica diferente a que estão acostumados.

\section{Do silêncio ao barulho silenciado}

Na primeira reunião intitulada Motivação e Atenção foi compartilhada a trajetória pessoal e profissional do oficineiro e obtidos após um silêncio, típico de um estranhamento inicial, os anseios bem como sugestões para atividades a serem realizadas. O resultado inicial foi positivo, pois a dificuldade notória do grupo em ler se materializou na resistência ainda maior da estudante " $D$ " que ficou tão feliz, pedindo ao final para a coordenadora de 
aprendizagem dizer à professora que havia sido a única campeã que não preencheu indevidamente o teste (fato justificado por não saber ler). As falas extraídas da primeira reunião mostraram que haveria uma dificuldade proeminente na montagem dos recursos escolhidos devido ao fraco potencial de leitura, tendendo ao analfabetismo o que justificou a escolha pelas representações artísticas.

Eles foram extremamente invasivos uns com os outros na hora da leitura de uma frase: "Quando um fala o outro abaixa a orelha, burra!" e "Não adianta nem perguntar tio, ela é burra e não sabe ler não! Melhor perguntar pra outro”. A falta de concentração e expressões que repetem uns com os outros desenharam um panorama reprodutor do estigma de derrotados. A oficina havia se transformado em mecanismo de coação e rotulada no imaginário escolar como um local de correção dos estudantes indisciplinados. Portanto, era necessário saber como eles se enxergavam diante dessa situação e como a escola os via simultaneamente, pois a fala do aluno evidenciou tais reflexões: "Esse foi o melhor castigo da minha vida! Quero sempre ser castigado desse jeito!’.

Durante a oficina $O$ espelho: como me vejo na escola? as crianças visualizaram imagens de situações escolares extremas (interessado $\mathrm{X}$ desinteressado; bagunceiro $\mathrm{X}$ comportado; e preguiçoso $\mathrm{X}$ dedicado) para que eles identificassem com quais se pareciam. Algumas perguntas foram direcionadas aos participantes ao visualizarem um espelho e as respostas culminaram em situações escolares diárias mais interessantes do que as aulas em si. A banda no dia dos ensaios para o desfile da independência, a liberdade no pátio da escola, as brincadeiras na sala, a música de cunho sexual são exemplos de fatores que contrastam com o desinteresse pelas aulas e seus grandes textos meramente para a cópia.

Segundo Larrosa (1994), a experiência de si é resultante da combinação de três pontos: as verdades do sujeito definidas pelos seus discursos, as práticas que regulam seu comportamento e as formas de subjetividade compondo o complexo processo de fabricação de si mesmo. Os lugares que se aprendem ou se modificam estas relações são chamados pelo autor de dispositivo pedagógico podendo ser pensados como constitutivos de subjetividades. Portanto, a educação e suas práticas tem papel fundamental na transmissão "objetiva" com uma experiência do mundo exterior e imprescindível na mediação da (des)construção de uma interioridade como "sujeitos" regidos pelas regras de comportamentos e de produção de subjetividades. Aquilo que somos depende indubitavelmente de como os outros nos enxergam ou de que imagem foi cristalizada no imaginário social. 
A partir dos levantamentos anteriores, imagens foram utilizadas na terceira oficina intitulada como Castigo x Elogio: trabalhando a partir dos extremos, objetivando extrair o entendimento deles sobre os dois conceitos. Nessa fase foram problematizadas as razões e as consequências que os levam a ser castigados ou elogiados. Quais atitudes eles (não) fazem para (não) serem castigados ou elogiados?

Contudo, ressalta Chervel (1988) que os programas oficiais, com sua finalidade educativa, e os resultados efetivos não prescritos constituem uma reelaboração da dinâmica cultural que a escola difunde e constrói simultaneamente. Sendo assim, as ações da escola e de seus agentes envolvidos, reforçados por seus mecanismos de adaptação e dominação, corroboram com a imagem estereotipada da inquietação causada pela presença instável deles na sala de aula, logo, a indisciplina desses alunos pode ser interpretada como uma ruptura da lógica fundante das relações pedagógicas estáveis nas escolas de ensino fundamental.

Porém ficou evidente que há dificuldades de expressão e veículos para canalizarem a suas opiniões diante de situações específicas, pois emanaram das narrativas situações ligadas ao tratamento (bom X mau) e correções corporais como agressões físicas no ambiente familiar sendo oportunas para o momento de diálogo. "Essa cicatriz que eu tenho aqui no ombro foi uma surra que minha mãe me deu e jogou um ferro que me pegou em cheio. Fui até parar no hospital!’”.
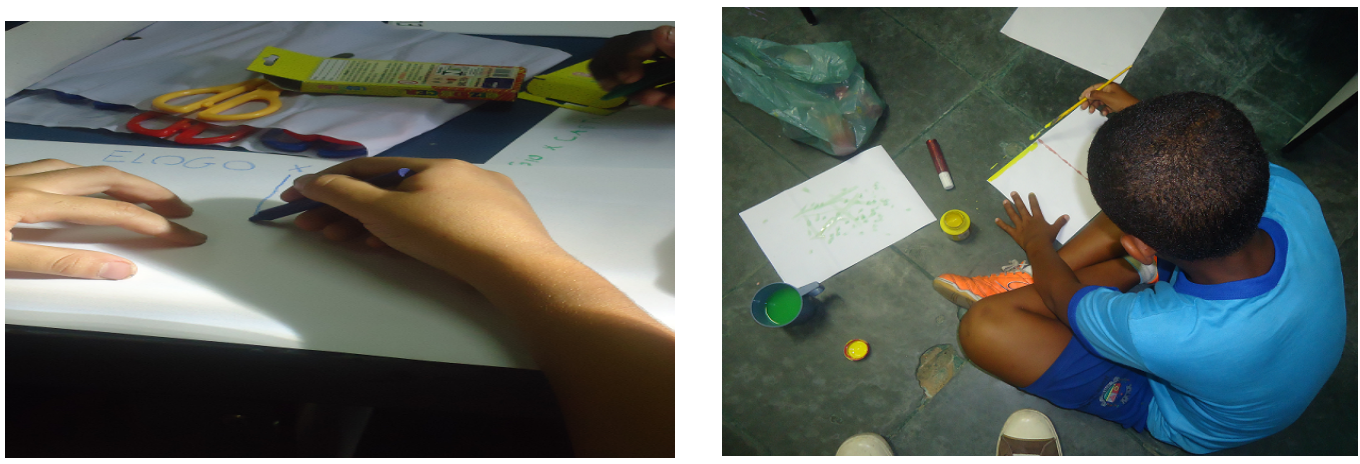

Figura 1 e 2 - Oficina Castigo x Elogio: trabalhando a partir dos extremos

Pautou-se, portanto, a discussão no sentido avaliar de quem é o direito à vida e o corpo do outro? Do trabalho com os desenhos, podemos extrair narrativas diversas de maus tratos físicos, violência verbal e, principalmente, privação dos jogos e brinquedos preferidos como forma de castigo. Tanto pelas representações quanto pelas colagens ficou notória a 
relação existente entre o elogio e o sucesso. As imagens retratadas por eles na seção de elogio relacionam, por exemplo, as fotos de jogadores famosos e personalidades (famílias) felizes.

Por outro lado, o castigo está ligado às manifestações de indisciplina, agressões físicas e privações impostas pelos adultos, no que diz respeito às vontades e resignações. O castigo está associado às expressões taxativas, por exemplo: "não pode", "proibido" "você não decide" e "sem fazer". Sendo assim, esse estudante que não é constantemente elogiado, mas cerceado das suas inquietações acaba por manifestar suas indignações ou discordâncias dentro da escola ou até em casa de maneira violenta. Seria possível expressar o desinteresse diferentemente da bagunça? Por que eles aterrorizam? Como é viver o lugar daquele que não consegue aprender?

Com base nos estudos sobre o cotidiano, queremos buscar caminhos a partir das táticas utilizadoras de Michel de Certeau e nos conceitos de estratégia e tática para entendermos a dinâmica de interação entre eles, pois "trata-se de combates ou de jogos entre o forte e o fraco, e das ações que o fraco pode empreender". Não podemos definir os "desenhistas do sete" como os "fracos" dada a fluidez das relações escolares. Nesse sentido, Certeau (1990) possibilita pensar na tensão entre as culturas infantis e a escolar, marcada pelo jogo de forças decorrente entre a estratégia, "organizada pelo postulado de um poder" e a tática determinada pela ausência de poder que deve jogar com o terreno imposto, tal como as curiosidades sexuais, levando à ideia da interioridade.

\section{O desvelar da paquera diante da sexualidade}

A partir de uma roda de conversas descontraídas na oficina Um diálogo entre o corpo e as sexualidades foi estabelecido um debate retomando os castigos físicos enunciados na reunião anterior, culminando na fala dos estudantes sobre experiências de sexualidade. As trocas discursivas e a linguagem do cotidiano nos permitem esmiuçar melhor as relações ideológicas presentes narrativas discursivas das crianças. Faraco (2003) esclarece que segundo Bakhtin e seus interlocutores as relações dialógicas são como espaços de tensão entre os enunciados, o que significa que esses podem coexistir e também provocar tensões numa intertextualidade dos discursos existentes. Emergindo num movimento de mão dupla questões sobre sexualidade num grupo definido como indisciplinado e vice-versa. 
Os exemplos citados por eles apontaram para uma associação da orientação sexual com o tipo de vestuário, alto grau de curiosidade pela masturbação, pelos filmes pornográficos, inclusive com experiências de descobertas e erotismo dentro e fora da escola. O tema apesar de despertar inquietação e indiscrição tornou o clima da oficina agitado, mas foi valorizado o momento para que eles falassem abertamente, sem nenhuma repressão, sobre as dúvidas, "(a)normalidades" e tabus sexuais que eles exemplificaram com muitos detalhesem muitos casos exímios conhecedores.

O desconhecimento sobre a própria sexualidade e a curiosidade típica dessa fase diante das mudanças do corpo aliada à ausência de espaços para conversa sobre tais assuntos contribuem para complexa relação subdimensionada da escola e até da família. Estas instituições socializadoras consentem um tratamento não circundado pela alteridade que afloram e são determinantes nessa fase identitária de um (pré) adolescente (como eles querem ser chamados na tentativa de se diferenciarem dos outros mais novos)

Sendo uma construção social que se dá em meio a troca nas suas relações familiares, sociais e também na escola por que há uma ausência de projetos pedagógicos com estes estudantes que trabalhe a diversidade sexual em seus três eixos previstos nos PCN? O conceito de sexualidade que pertence a nossa história nasceu como a justa medida de separação entre normalidade e anormalidade (FOUCAULT, 1984). Por este prisma, o sexo está limitado à percepção biológica dos sujeitos: masculino/feminino, heterossexual/ homossexual e normal/anormal. Neste sentido, a fluidez das identidades sexuais se dá a partir de várias instâncias sociais e culturais, bem como sua diversidade.

A teoria queer, que em inglês significa estranho, esquisito, este vocábulo foi reapropriado e produziu uma "epistemologia", ou um conjunto de articulações intelectuais, questionando o "aprisionanento da concepção de corpo no sistema heteronormativo de sexogênero-desejo" (SPARGO, 2007). Essa teoria questiona as condições de possibilidade do conhecimento que produz a norma sexual e social, vai se referir à questão da relatividade da normalidade e da construção cultural das diferenças.

Na oficina nomeada como As roupas e a Paquera a dinâmica utilizando o material didático desenvolvido como elemento gerador da roda de conversas sobre os gêneros acabou sendo utilizado para demonstrar as técnicas de paquera com os bonecos(as) e como essas táticas facilitam a conquista daquele(a) que desejamos. Ao final, eles utilizaram os bonecos 
como artifícios (escudos) para interagirem transparecendo suas emoções (inclusive de interesse entre dois participantes). Houve uma timidez e a dificuldade de expressão no momento da conquista até o momento da indagação que norteou o encontro: "Só com a roupa que eu visto né eu consigo "pegar" um garoto bonitinho né? Silva corrobora com as constatações dessa oficina ao afirmar:

Quando somos crianças, a curiosidade sexual se expressa por meio de perguntas e, principalmente, por meio de jogos e brincadeiras. A brincadeira sexual tem para a criança um sentido diferente daquele que é dado pelo adulto e é fundamental e sadia para seu desenvolvimento emocional e intelectual. (SILVA, 2007, p.19)

Questões sexuais foram predominantes e tratadas por eles como brincadeiras, mas na verdade eles possuem o entendimento dos termos, gírias, gestos, problemáticas levantadas e adquiridas nas relações sociais que não são abordadas, segundo eles mesmos, na escola. Ao respondermos atenciosamente às indagações, sexuais ou não, aliviamos as tensões e potencializamos questionamentos futuros cada vez mais complexos sobre si mesmos e sobre o mundo que os cerca.

Algumas revistas foram entregues para que eles manuseassem durante a oficina de $\mathrm{O}$ sexo biológico e os gêneros sexuais e algumas reações preconceituosas no comportamento foram notadas, principalmente, quanto aos termos (bichas, traveco, sapatão e veadinho) referenciando os indivíduos representados nas publicações. "Ao se falar em gênero, não se fala apenas de macho ou fêmea, mas de masculino e feminino, em diversas dinâmicas de masculinidades e feminilidades" (SCOTT, 1995:72 e DE LAURETIS:1986:12). Foi solicitado dos estudantes que eles falassem sobre as orientações sexuais, rapidamente eles recorreram aos livros de ciências para explicar o sexo biológico (masculino e feminino) sem saber a diferença entre gêneros sexuais e sexo anatômico que foi trabalhada durante o encontro.
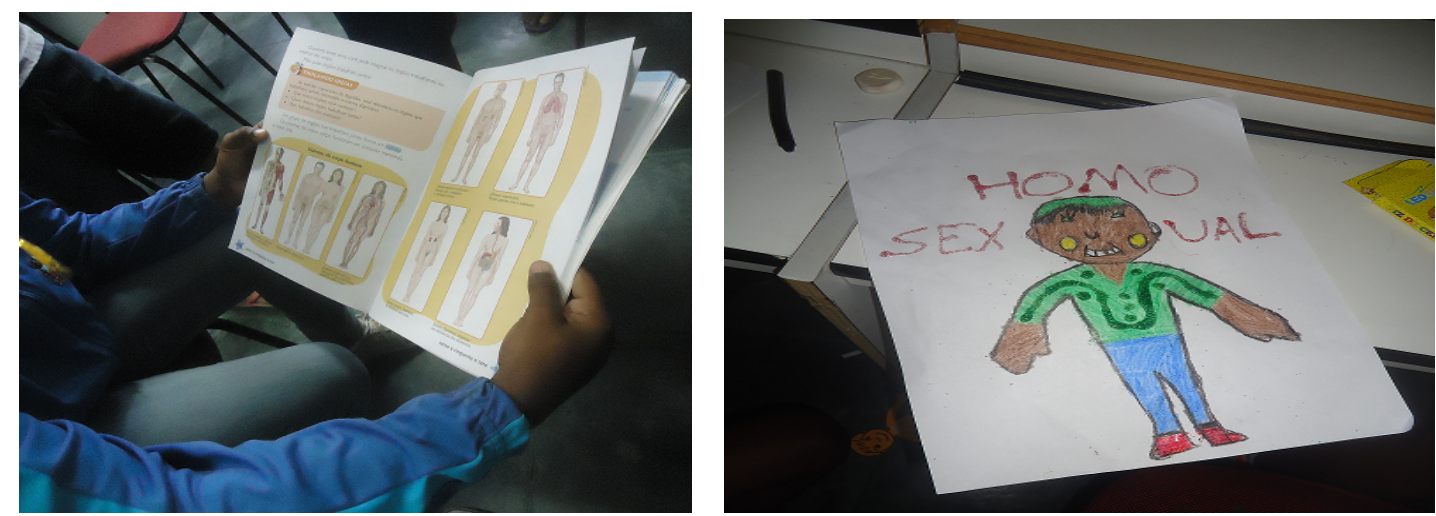
Figuras 3 e 4 - Oficina:O sexo biológico e os gêneros sexuais

A oficina tinha por objetivo identificar o universo vocabular e o conhecimento sobre as identidades sexuais para que com a orientação sexual (OS) abordando as identidades sexuais (homossexual, heterossexual e bissexual) fosse possível diminuir as agressões existentes utilizando os termos vulgares referentes à sexualidade, que não são exclusivos à escola, mas perpassam estes ambientes sendo silenciados e, segundo eles, são proibidos nas salas sendo passível de castigo.

Outro ponto importante foi lembrá-los que a Organização Mundial de Saúde (OMS) não aceita que a homossexualidade seja considerada doença e, por isso, em 1990, excluiu-a do Código Internacional de Doenças (CID). Prefere-se, portanto o uso do termo homossexualidade e em oposição a homossexualismo em que a desinência "ismo" atribui um caráter de doença, distúrbio ou perversão. No transcorrer da oficina cantos de músicas de funk foram ouvidos, alguns termos que envolvem o ato sexual fazem parte do vocabulário deles: “A camisinha estourou nasceu neném, esse filho não é meu, esse filho é de quem?" Dessa forma, foi utilizado como mote para o pesquisador fazer parte das conversas paralelas até que os estudantes estabeleceram um diálogo rico e, ao mesmo tempo, falaram sobre sexualidade:

(Oficineiro) - Vocês sabem para que serve essa camisinha?

- Camisinha é negócio para homem (Estudante 1)

- E para viado também!

(Oficineiro)- Os homossexuais! Aqueles que sentem atração por alguém do mesmo sexo, lembram?

- Mas os homossexuais não precisam né, porque é um chupando o outro!.

(Oficineiro) - Chupando o que?

- O piru ué! (Apontou o estudante para sua região genital)

(Oficineiro)- Você sabe o que é isso?

- Ué! Piru é o que sai goza, leite!

-Que se joga na cara, mas não se engole. Respondeu a garota.

(Oficineiro)- Por que não engole?

-Pode engravidar né! Mas é só na hora de gozar. Igual nos filmes quando joga na cara! 
Na sétima oficina que teve como título: A nudez erótica e a artística o trabalho foi planejado tendo como base as inúmeras experiências dos estudantes em contato com material pornográfico narradas com grau de detalhes impactante. Os objetivos eram diferenciar o erotismo da sexualidade e a nudez artística da pornografia. Entendendo que sexualidade é muito mais do que prazer corporal ou sexual. Ela é a energia que nos motiva encontrar o amor, ao contato e intimidade, se expressa na forma de se tocar e tocar os outros.

Apresentamos pinturas célebres e cenas clássicas de nudez como a personagem Rose do filme Titanic se despindo e outra do mesmo filme já como modelo de nu artístico. Eles relataram situações de dúvidas e curiosidades no âmbito sexual (sexo oral, anal, incesto, pedofilia, homofobia, assédio sexual e prostituição). Muitas foram respondidas por uma estudante, conhecedora do assunto, afirmando que por ver frequentemente filmes em canais adultos com sua prima sabia de tantos detalhes. Na fala dela momentos de contatos corporais entre as duas durante a exibição dos filmes pornográficos eram constantes, principalmente, quando viam duas mulheres lésbicas como personagens. Outras narrativas mostraram o jeito peculiar deles explicarem tais assuntos:

-Tio, você sabe como se faz um filho?

(Oficineiro)-Não! Explica!

- Poxa, é muito simples! Tocando punheta e jogando na buceta da mulher. A estudante falou tocando nas suas partes intimas.

(Oficineiro)-Como aprendeu isso, foi na escola ou com seus pais?

-Claro que não né! Essas coisas a gente não fala como os pais! Vemos no sex hot!

A sexualidade suscita mecanismos diferenciados de controle e de dissuasão que se complementam, instituindo ao indivíduo dispositivos de vigilância. De que forma a sexualidade e seus reflexos ditos indisciplinados atravessa o espaço escolar, penetra no imaginário social? Essa pergunta necessita de mais reflexões e análises em diferentes ambientes escolares, haja visto que na última oficina: Ser criança/ser adolescente o fato de não se falar dessas questões foi encarado como forma intencional de ainda tratá-los como “criancinhas", mas não se sentem maduros como adolescentes para uma conversa mais aberta sobre as sexualidades.

\section{Os impactos do projeto}


O resultado das ações desenvolvidas foi extremamente positivo, era possível ver o trabalho em equipe sendo articulado sem a necessidade de uma mediação do oficineiro, bem como o compartilhamento dos materiais utilizados nas atividades. Os relatos das professoras corroboraram com a constatação obtida nos encontros, como podemos analisar nas seguintes falas: "Colaborou com a união do grupo, na organização entre eles e para expor ideias" $e$ "eles ficaram mais interessados em participar de atividades em grupo e desenvolveram um pouco a capacidade de esperar e de ouvir o outro".

Enxergaram nas atividades um local "seguro" para a fala sobre sexualidade e até sobre a indisciplina. As atividades artísticas potencializadas possibilitaram abordar as aflições e descontentamentos com as regras e atitudes presentes no instituído escolar que os definiam com os que "pintavam o sete" numa perspectiva que torna válida a afirmação de Leonardo Da Vinci: “A arte diz o indizível; exprime o inexprimível, traduz o intraduzível”. Acima de tudo, houve uma aceitação gradual da dinâmica empregada que resultou no pleito deles por mais tempo de oficina e na realização das atividades ao ar livre. Nesse trecho: "aqui é bom, porque a gente fala das coisas e ainda aprende brincando e desenhando" a oficina se configura como um momento descontraído, onde os conteúdos se relacionam com a vida deles, assim as problemáticas trocadas e divididas tornam a aprendizagem mais participativa e interessante.

\section{Considerações finais}

O programa do PIBID se consolidou como uma iniciativa eficaz e enriquecedora para todos os envolvidos, tanto para os bolsistas que experimentaram as problemáticas típicas do exercício do magistério como para a instituição escolar que, imersa na rotina escolar já cristalizada, teve suas práticas re-pensadas criticamente, sob a ótica do "chão da escola" dentro da perspectiva de que a indisciplina pode e tem muito a dizer sobre como as relações professor-aluno precisam ser questionadas constantemente sem estabelecer relações de poder que possam inibir ou reprimir o protagonismo da criança nessa relação.

O processo educativo que contemple a Orientação Sexual (O.S.) fornece condições de aprendizagem mais abrangentes em termos de descobrimento do próprio corpo e se justifica nos tempos em que relações afetivas são regidas por inferências midiáticas. A educação sexual no contexto escolar atual se configura como grande ferramenta válida para revermos nossos mecanismos de (re)produção da normatização sexual e de outras categorias, 
sendo possível transformá-la em ato político de respeito à diversidade sexual, étnica, religiosa, racial, enfim, das pessoas seja qual for nossas diferenças.

Apesar do embate ideológico ainda presente nas relações interpessoais que constituem a imagem idealizada da criança como ser assexuado, aprender como cuidar do próprio corpo não significa estimulo sexual precoce, mas autoriza os sujeitos a exercer um papel ativo sobre sua própria sexualidade, consolidando-a como matriz do seu prazer, torna-os mais críticos frente aos ditames preconceituosos da nossa sociedade e autônomos para buscarem apoio em possíveis casos de abuso sexual.

A associação da indisciplina e o "afloramento" da sexualidade só se tona possível com um olhar mais aguçado e investigativo destas relações latentes no cotidiano escolar extremamente silenciador. O trabalho com uma parcela menor da turma fomentou um fortalecimento do espírito de equipe e redesenhou a imagem de um grupo fortemente estigmatizado pela bagunça- apresentando aspirações e emergências sexuais antes desprezadas.

\section{Referências Bibliográficas}

CERTEAU, Michel de. A invenção do cotidiano. Rio de Janeiro: Vozes, 1990.

CHARLOT, B. A violência na escola: como os sociólogos franceses abordam essa questão Sociologias, Porto Alegre, ano 4, n. 8, p. 432-443, jul/dez 2002.

CHERVEL, André. L'histoire des disciplines scolaires. Paris: Histoire de L'educacion, n. 38, 1988, p. 59-119.

DE LAURETIS, Teresa (Ed.). Feminist Studies/Critical Studies. Bloomington and Indianapolis: Indiana University Press, 1986.

FARACO, Carlos Alberto. Linguagem e diálogo: as ideias linguísticas de Bakhtin. Curitiba: Criar Edições, 2003.

HECKERT, A. L. C. (2004). Narrativas de Resistência: educação e políticas. Tese de Doutorado, Programa de Pós-Graduação em Educação, Universidade Federal Fluminense, Niterói, RJ.

LARROSA, Jorge. Tecnologias do eu e educação. In: SILVA, Tomaz T. (Org.). O sujeito da educação: estudos foucaultianos. 2. ed. Petrópolis: Vozes, 1994. 
LOURO, Guacira Lopes. Um corpo estranho. Ensaios sobre sexualidade e teoria queer. Belo Horizonte: Autêntica, 2004.

SILVA, M.C.P. (Org.) Sexualidade começa na infância. São Paulo: Casa do Psicólogo, 2007. SPARGO, Tamisin. Foucault y la teoria queer. Barcelona: Gedisa, 2007.

\footnotetext{
i Graduando em Pedagogia - UFRRJ-IM
} 